\title{
Malnutrition in Community-Dwelling Anorexia Nervosa Patients: Alterations of Physical and Laboratory Features
}

\author{
Maria Gabriella Gentile*, Giulia Maria Manna, Laura laccarino, Luisa Cometto, \\ Nicoletta Mariani and Chiara Lessa
}

\author{
Eating Disorder Unit, Niguarda Hospital, Piazza Ospedale Maggiore 3, 20162 Milan, Italy

\begin{abstract}
Background and aims: Malnutrition in Anorexia Nervosa may determine many abnormalities and consequences for both physical and psychological points. Their early detection and management may improve the prognosis.

This study aims at identifying clinical predictors of disease highlight possible correlations between signs-symptoms and degree of malnutrition.
\end{abstract}

Methods: The authors present a retrospective study of 302 Anorexia Nervosa outpatients aged $23.2 \pm 9.4$ years (X) \pm SD) observed at arrival in Eating Disorder Unit.

Results: 302 patients were examined, (BMI $14.7 \pm 1.9 \mathrm{~kg} / \mathrm{m}^{2}$ ). We observed a significant reduction of measured basal metabolic rate (less $19.3 \pm 15.3 \%$ ) in almost all patients, and almost one patient over four have some clinical complications such as bradycardia, hypotension, anemia, hypoglycemia, showing a high correlation with malnutrition degree.

Conclusions: Determining malnutrition degree is relevant to identify and to treat Anorexia Nervosa patients as well as to contract setting of care with patients and parents for reducing delayed treatment.

Keywords: Anorexia nervosa, malnutrition, clinical alteration, physical and laboratory features.

\section{INTRODUCTION}

Anorexia Nervosa (AN) is a serious, potentially lifethreatening illness characterized by severe malnutrition, with abnormally low body weight (BMI $<17.5 \mathrm{~kg} / \mathrm{m}^{2}$ or body weight at least $15 \%$ below the expected value), with an intense fear of weight gain and an undue emphasis on weight and shape in selfevaluation [1-3].

Amenorrhea (i.e. loss of three consecutive menstrual cycles) is currently required for the diagnosis of $\mathrm{AN}$, but often is hidden by contraceptive drugs. AN can cause significant clinical complications in every organ system, particularly relevant in adolescents in the growing and developing body with slowing in linear growth, impaired bone mineral accretion, structural and functional damage of the brain [4-7].

Early detection and management of an eating disorder may prevent the physical and psychological consequences of malnutrition such as obsessivecompulsive disorder, anxiety, depression and social isolation. All of these as well other perpetuating factors allow the progression of the disease to a later stage [811].

*Address corresponding to this author at the Eating Disorders Unit, Niguarda Hospital, Piazza Ospedale Maggiore 3, 20126 Milan, Italy; Tel: +39 026444 2839; Fax: +39 026444 2593; E-mail: centrodca@ospedaleniguarda.it
Most studies suggest that a short duration of symptoms before treatment results in a favorable outcome. A propos, it should be recalled that the today full recovery rate of AN is no higher than $40-50 \%$ [1218].

Unfortunately, the diagnosis of AN can be elusive. More than one-half of all cases go undetected for a long period of time. This is in contrast to most patients with loss of weight for other medical conditions (i.e. hyperthyroidism, malignancy, etc) who express concern over their weight loss, patients with $\mathrm{AN}$ are actively pursuing an abnormally low body weight, usually hide their illness and deny their symptoms, hampering the collection of their medical history [19].

A further important barrier to help-getting AN patients is likely poor identification and knowledge about the disease by medical doctors particularly in primary care by general practitioners who should be the gatekeepers to specialist care $[20,21]$.

The present investigation aims at identifying malnutrition signs and clinical predictors of the disease which can be collected at every point of entry into the health care system. More specifically, focusing on the outpatient setting which will give detailed description of clinical features checking by physical and laboratory examinations of outpatients affected by AN and highlight possible correlations between signs-

๑) 2012 Lifescience Global 
symptoms and the degree of malnutrition measured by BMI.

\section{PATIENTS AND METHODS}

\subsection{Patients}

The clinical records of 302 females aged $23.2 \pm 9.4$ years affected by AN as diagnosed by Diagnostic and Statistical Manual of Mental Disorders Fourth Edition criteria were reviewed [22].

Eligible to the study were the patients seeking care at the outpatient clinic for eating disorders of the Niguarda Hospital in Milan (Italy) from January 2007 to May 2010.

All patients initially received a clinical diagnosis by a medical doctor specialized in clinical nutrition with expertise in assessment of patients with eating disorders.

Male patients were excluded from analyses because of their small number.

\subsection{Measurements}

\subsubsection{Anthropometry}

Nutritional evaluation by antrhopometry was performed by a registered dietitian.

Body weight was recorded to the nearest $100 \mathrm{~g}$ using a standard physician's weighing scale with barefoot patients wearing only underwear. Height was determined to the nearest $0.5 \mathrm{~cm}$ on a standard stadiometer.

\subsection{Basal Metabolic Rate}

Basal metabolic rate: resting gas exchange was measured by open circuit, indirect calorimetry (Sensor Medics) for 30 minutes. Before each measurement, the system was recalibrated using a reference gas mixture of $95 \% \mathrm{O}_{2}$ and $5 \% \mathrm{CO}_{2}$.

A complete medical history was taken to determine illness durations, menstruation, evaluation of primary clinical variables such as heart rate, systolic and diastolic blood pressure.

\subsection{Blood Samples}

Blood samples were usually taken by an antecubital vein puncture. Blood-plasma-serum values were determined by the hospital laboratory according to published methods.

\subsection{Data Analysis}

The mean values, standards deviations, frequencies, regression statistics with their associated probability levels were obtained by the corresponding "procedures" of SAS ver. 9.1. The linear model was applied for regression.

\section{RESULTS}

Three hundred two patients were eligible for the study. Mean BMI was $14.7 \pm 1.9 \mathrm{~kg} / \mathrm{m}^{2}$ (range 9.7-17.5 $\mathrm{kg} / \mathrm{m}^{2}$ ) and the mean age $23.2 \pm 9.4$ years.

The treatment statistic of 302 patients prior to their evaluation to our outpatient unit was:

the $39 \%$ had no previous treatment at all, the $33 \%$ had mono-disciplinary outpatient treatment, the $22 \%$ had been treated in inpatient units, for the $6 \%$ no data of previous treatment was available.

A summary of patient's anamnestic demographic and clinical characteristics is reported in Table $\mathbf{1 .}$

The arrival to our outpatient unit happened more than four years after the estimated outset of the illness; 271 patients were amenorrhoic, 9 were prepuberal and 22 were on estroprogestin therapy.

We observed a clinically significant reduction of measured metabolic basal rate $(-19.3 \pm 15.3 \%)$.

Table 2 shows the mean values and Standard Deviation of haematological parameter and biochemical values of 302 AN patients. Sexual hormonal values are referred to the 271 amenorrhoic patients.

Table 3 shows the percentages of abnormal (- abnormally low or high compared to the standard or usual normal clinical values -) values of the vital signs and biochemical values of whole population (302 patients), of 97 patients with $\mathrm{BMI}>16 \mathrm{~kg} / \mathrm{m}^{2}$ - mean BMI $16.8 \pm 0.2 \mathrm{~kg} / \mathrm{m}^{2}$-(subgroup 1) and of 205 pts with BMI $\leq 16 \mathrm{~kg} / \mathrm{m}^{2}-$ mean BMI $13.7 \pm 1.6 \mathrm{~kg} / \mathrm{m}^{2}-$ (subgroup 2).

Both sets of values, vital signs and laboratory values are significantly more altered in AN with more severe malnutrition (subgroup 2), than in subgroup 1 pts where many values, but not all, are in normal range. 
Table 1: Anamnestic, Demographic and Clinical Data of 302 Anorexia Nervosa Patients ${ }^{\mathrm{a}}$

\begin{tabular}{|c|c|c|c|}
\hline & Mean & S.D. & Range \\
\hline Number of patients & 302 & & \\
\hline Age at reported onset of Anorexia Nervosa & 18.2 & 6.7 & $(8-40.1)$ \\
\hline Duration of disease (months) & 56.5 & 72.2 & $(3-357)$ \\
\hline Age (years) of admission & 23.2 & 9.4 & $(8.3-48)$ \\
\hline Body Mass Index $\left(\mathrm{Kg} / \mathrm{m}^{2}\right)$ & 14.7 & 1.9 & $(9.7-17.5)$ \\
\hline Body weight $(\mathrm{Kg})$ & 38.5 & 6.9 & $(19.2-56.8)$ \\
\hline Height (cm) & 161.3 & 8.5 & $(123.5-188)$ \\
\hline Heart rate (beats/min) & 63.8 & 12.3 & $(33-112)$ \\
\hline Systolic blood pressure $(\mathrm{mmHg})$ & 96.0 & 12.9 & $(70-160)$ \\
\hline Diastolic blood pressure $(\mathrm{mmHg})$ & 58.6 & 10.7 & $(40-90)$ \\
\hline Amenorrhea (No.) & 271 & & \\
\hline Prepuberal (No.) & 9 & & \\
\hline Estimated resting metabolic rate (Kcal/24h) & 1218.9 & 104.0 & $(867-1655)$ \\
\hline Measured resting metabolic rate (Kcal/24h) & 982.2 & 194.1 & $(526-1798)$ \\
\hline $\begin{array}{l}\% \text { Difference versus estimated basal metabolic rate according to } \\
\text { Harris Benedict formula }\end{array}$ & -19.3 & 15.3 & $(-47-98)$ \\
\hline
\end{tabular}

${ }^{a}$ Values are means \pm SDs, ranges in parenthesis.

Table 2: Haematological Parameters and Biochemical Values in 302 AN Patients $^{a}$

\begin{tabular}{|c|c|c|}
\hline Red blood cells $\left(4-5.310^{12} / L\right)^{b}$ & 4.3 & 0.5 \\
\hline Hematocrit (37 - 46\%) & 38.4 & 4.8 \\
\hline White blood cells $\left(4-1010^{9} / \mathrm{L}\right)$ & 5.3 & 1.8 \\
\hline Platelets $\left(140-44010^{9} / \mathrm{L}\right)$ & 238.2 & 75.6 \\
\hline Lymphocytes (1.5-5 10\%/L) & 2.8 & 0.7 \\
\hline Glucose (70-110 mg/dL) & 75.7 & 13.8 \\
\hline Insulin $(2-20 \mu \mathrm{U} / \mathrm{mL})$ & 5.8 & 7 \\
\hline Y-Glutamyl transferase $(2-35 \mathrm{U} / \mathrm{L})$ & 21.6 & 19.7 \\
\hline Uric acid (1.5-5.7 mg/dL) & 3.6 & 1.1 \\
\hline Amylase (28-100 U/L) & 95.3 & 44.2 \\
\hline Total plasma cholesterol (<190 mg/dL) & 180.4 & 44 \\
\hline Plasma HDL-cholesterol (>42 mg/dL) & 70.6 & 18.3 \\
\hline Plasma triglycerides (<180 mg/dL) & 85.3 & 40.2 \\
\hline Tri-iodothyronine (1.8-4.5 pg/mL) & 2.5 & 1.9 \\
\hline Tetra-iodothyronine (9.2-17 pg/mL) & 11.5 & 4.3 \\
\hline
\end{tabular}


(Table 2). Continued.

\begin{tabular}{|c|c|c|}
\hline & Mean & S.D. \\
\hline Total proteins $(6.4-8.3 \mathrm{~g} / \mathrm{dL})$ & 7.4 & 0.8 \\
\hline Transferrin (200-374 mg/dL) & 237.6 & 60.7 \\
\hline Albumin (3.5-5.3 mg/dL) & 4.9 & 0.5 \\
\hline Sodium (132-143 mmol/L) & 140.4 & 3.4 \\
\hline Potassium (3.4-5.2 mmol/L) & 4.3 & 0.5 \\
\hline Chloride (96-107 mmol/L) & 101.7 & 5 \\
\hline Bicarbonate (22-30 mmol/L) & 28.1 & 3.9 \\
\hline Calcium (8.5-10.5 mg/dL) & 9.5 & 0.6 \\
\hline Phosphorus (3-4.5 mg/dL) & 3.9 & 0.7 \\
\hline Magnesium (1.5-2.0 mEq/L) & 1.7 & 0.2 \\
\hline Iron $(50-150 \mu \mathrm{g} / \mathrm{dL})$ & 88.4 & 33 \\
\hline Ferritin (13-150 ng/mL) & 95.2 & 105 \\
\hline Prolactin $(3.4-24.1 \mathrm{ng} / \mathrm{mL})^{c}$ & 14.7 & 17.4 \\
\hline Follicle-stimulating hormone $(1.7-21.5 \mathrm{UI} / \mathrm{L})^{c}$ & 6.3 & 15.9 \\
\hline Luteinizing hormone $(1-95.6 \mathrm{UI} / \mathrm{L})^{\mathrm{c}}$ & 3.4 & 7.5 \\
\hline Estradiol $(24-411 \mathrm{pg} / \mathrm{mL})^{\mathrm{c}}$ & 42.4 & 83.9 \\
\hline Progesterone $(0.3-4.2 \mathrm{ng} / \mathrm{mL})^{\mathrm{c}}$ & 0.9 & 2.5 \\
\hline
\end{tabular}

${ }^{a}$ Values as means \pm SDs.

${ }^{\mathrm{b}}$ Reference range shown in brackets

'Sexual hormone values are referred to 271 amenorrhoic pts.

In Table 4 we show the prevalence of clinical features: almost one patient over four have some clinical complications. Vital signs of the 302 participants are as follows: $29.1 \%$ had hearts rate below normal (< 60 beats per minute), $9.3 \%$ has heart rates of less than 50 beats per minute and $2 \%$ had heart rates less than 40 beats per minute; $24.5 \%$ had systolic blood pressure less than $90 \mathrm{mmHg}$ and $13.5 \%$ diastolic blood pressure less than $50 \mathrm{mmHg}$.

Hyperamylasemia was found in 36 percent of patients and may be considered as a consequence of vomit in purging subtype of AN patients; both frequency and type of vomiting seem to be correlated to salivary gland enlargement and hyperamylasemia [23].

Correlations of vital signs, basal metabolic rate and laboratory results with BMI, are shown in Table 5 which reports the R-squared value (i.e. amount of variance explained by BMI) and the probability level for the hypothesis of no linear correlation .

We found a highly significant correlation between the degree of malnutrition, as indicated by level of BMI, and blood pressure, anemia, level of triiodothryronine, transferrin and some indicators of liver function.

The most consistent correlation was found between measured resting metabolic rate and level of BMI.
Other authors described medical findings in AN patients, but our results represent, as far as we know, the largest case study on clinical findings in outpatients with AN [24, 25].

\section{DISCUSSION}

As AN patients often do not make their eating disorder and low body weight the subject of discussion, the physician is forced to rely on physical examination, metabolic and laboratory parameters as diagnostic hints.

In our study of 302 women with AN living in the community were found with a high prevalence of clinical findings, which are to be considered as effects of starvation of the body and should be regarded to guide physical aspects of care [26], because early intervention might be expected to exert positive effect, as indeed this was evident in many studies $[14,17]$.

All clinical evaluations used in this study, except for measured basal metabolic rate, particularly used during treatment to establish the amount of caloric intake to avoid refeeding syndrome [27], may be easily used at every point of entry into the health care system even by general practitioners and they may be useful to the physician to elicit the patient's physical concerns and to patient being treated. 
Table 3: Percentage of Abnormal Vital Signs and Laboratory Values in all 302 Patients and in 2 Different BMI Subgroups ${ }^{\mathrm{a}}$

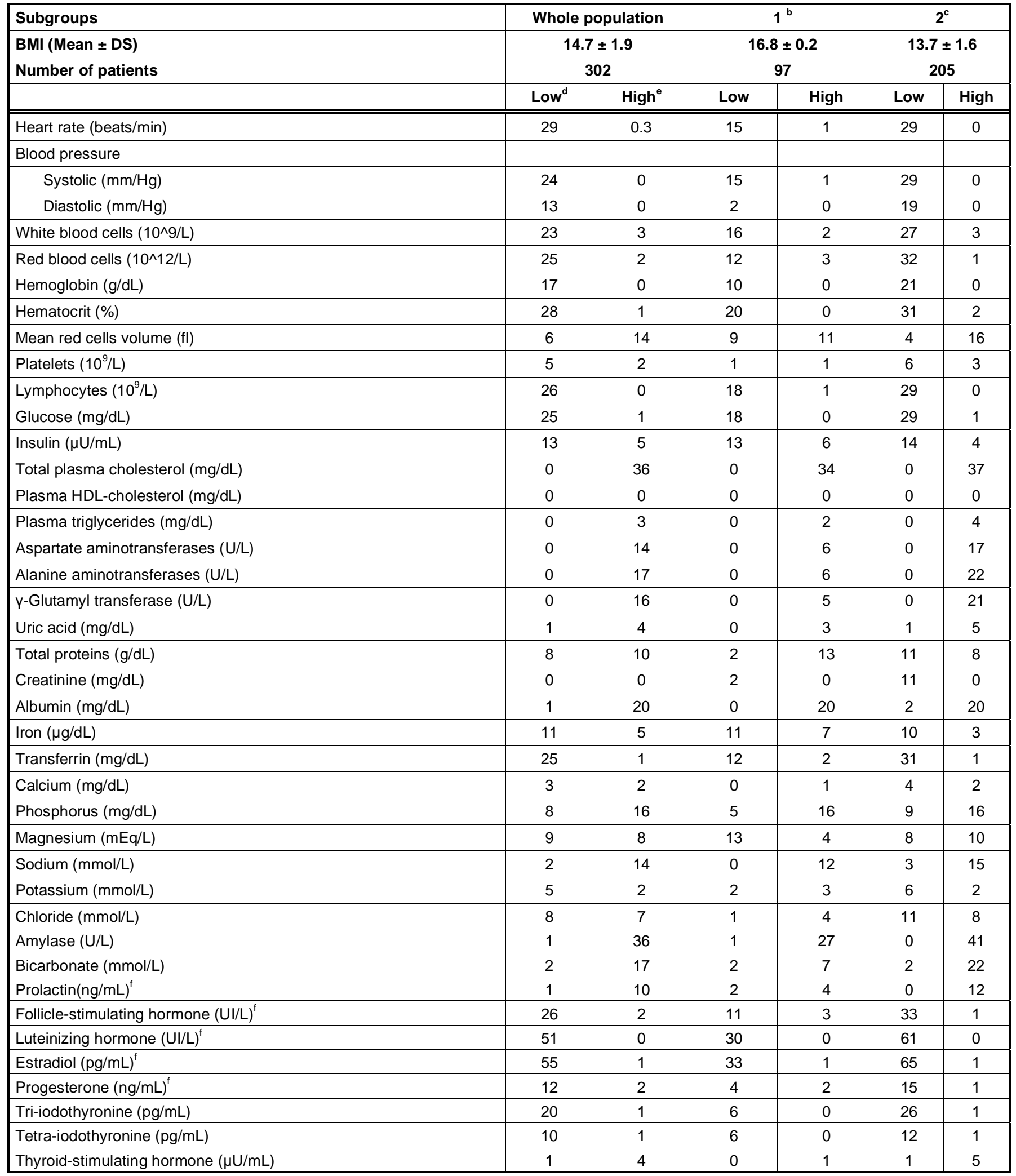

${ }^{a}$ Results of vital signs and laboratory values are expressed as percentage of patients. Percentage rounded to the first integer digit

${ }^{\mathrm{b}}$ Subgroup 1 = BMl above $16 \mathrm{~kg} / \mathrm{m}^{2}$ AN patients.

${ }^{\mathrm{c}}$ Subgroup 2 = BMl below or equal $16 \mathrm{~kg} / \mathrm{m}^{2}$ AN patients.

'Low $=$ Low compared to normal values.

${ }^{\mathrm{e}} \mathrm{High}=$ High compared to normal values.

fSexual hormone values are referred to 271 amenorrhoic pts. 
Table 4: Medical Complications in 302 Patients with Anorexia Nervosa

\begin{tabular}{|c|c|c|}
\hline & Frequency $^{a}$ & Percentage $^{b}$ \\
\hline Pulse $<60 \mathrm{~min}$ & 88 & 29 \\
\hline Pulse $<50 \mathrm{~min}$ & 33 & 9.3 \\
\hline Pulse $<40 \mathrm{~min}$ & 5 & 1.7 \\
\hline Diastolic blood pressure $(<50 \mathrm{~mm} / \mathrm{Hg})$ & 40 & 13.5 \\
\hline Anemia (Red blood cells <4 10^12/L) & 75 & 25 \\
\hline Hypoglicemia (<70 mg/dL) & 75 & 25 \\
\hline Hypotrasferrinemia (<200 mg/dL) & 75 & 25 \\
\hline Aspartate aminotransferases (>40 U/L) & 42 & 14 \\
\hline Alanine aminotransferases (>45 U/L) & 51 & 17 \\
\hline Y-Glutamyl transferase (>35 U/L) & 48 & 16 \\
\hline Hyperamilasemia (>100 UL) & 108 & 36 \\
\hline Low measured respect to estimated resting metabolic rate & 294 & 97.5 \\
\hline
\end{tabular}

${ }^{a}$ Frequency equal numbers of patients.

${ }^{\mathrm{b}}$ Percentage rounded to the first integer digit.

${ }^{\mathrm{C}}$ Reference values in parenthesis.

Table 5: Regression of Medical Findings with BMI

\begin{tabular}{|l|c|c|}
\hline Response variable & R Square & P Value \\
\hline \hline Heart Rate & 0.001 & 0.8 \\
\hline Systolic Blood Pressure & 0.09 & 0.0001 \\
\hline Diastolic Blood Pressure & 0.10 & 0.0001 \\
\hline Measured resting metabolic rate & 0.32 & 0.0001 \\
\hline Red blood cells & 0.11 & 0.0004 \\
\hline Hematocrit & 0.03 & 0.04 \\
\hline White blood cells & 0.06 & 0.09 \\
\hline Lymphocytes & 0.02 & 0.04 \\
\hline Tri-iodothyronine & 0.02 & 0.002 \\
\hline Transferrin & 0.11 & 0.001 \\
\hline Glucose & 0.01 & 0.07 \\
\hline Aspartate aminotransferasi & 0.04 & 0.01 \\
\hline Alanine aminotransferasi & 0.07 & 0.001 \\
\hline Y-glutamyltrasferasi & 0.15 & 0.0009 \\
\hline
\end{tabular}

Treatment should be given by health care providers who have expertise in managing patients with eating disorders; management should be multidisciplinary and is best accomplished by a team consisting of medical, nutritional, nursing and mental health disciplines.
Contract setting of care is important for patients with AN, and the possibility to present the clinical findings to patients and parents prove to be very useful to determine the level of treatment (outpatient - inpatient) and the need for hospitalization, particularly for primary 
care physician, but also for multidisciplinary team of Eating Disorders Unit [1, 2, 3].

In these 302 AN patients we proposed an extended outpatient treatment with a multidisciplinary treatment to the subgroup 1 (which presented a mild degree of malnutrition). In subgroup 2, having more an evident degree of malnutrition, we proposed an inpatients treatment with intensive day hospital therapy to 56 patients and a day and night treatment for 1-2 months and then a day hospital therapy to 149 inpatients, following our specific protocol of care [27, 28].

A limitation of our study was that the patients were recruited in outpatient ambulatory of Eating Disorders Unit; nevertheless these findings suggest that a clinical evaluations of all women with $\mathrm{AN}$ is fundamental and should proceed in correlation with psychological evaluation and treatment.

Clinical evaluations prove also essential to reduce and/or avoid delayed treatment, that so far have been frequently described, as also recently it was showed in a French multicenter study about AN patients treated in intensive care unit which report admission from home for $53 \%$ of patients and a crude mortality about $10 \%$ $[29,30]$.

\section{CONFLICT OF INTEREST}

The authors have no conflict of interest.

\section{STATEMENT OF AUTHORSHIP}

The authors' responsibility were as follows:

Maria Gabriella Gentile, MD, organized and supervised clinical evaluation and treatment, organized and reviewed data analysis and literature research, wrote the manuscript.

Giulia Maria Manna, MD, supervised the evaluation of subjects with anorexia nervosa and reviewed data analysis.

Laura laccarino, MD, collected clinical data of subjects.

Luisa Cometto, RD, collected anthropometric data and diet habits of subjects.

Nicoletta Mariani, RD, collected anthropometric data and diet habits of subjects.

Chiara Lessa, RD, collected anthropometric data and diet habits of subjects.
All authors read and approved the final manuscript.

\section{ACKNOWLEDGMENTS}

We acknowledge the support of the FOBAN (Obesity, Bulimia, Anorexia Nervosa and Nutrition Foundation) which supported the preparation of this manuscript.

\section{REFERENCES}

[1] Wilson G0T, Shafran R. Eating disorders guidelines from NICE. Lancet 2005; 365(9453): 79-81.

[2] Practice guideline for the treatment of patients with eating disorders. American Psychiatric Association Work Group on Eating Disorders 2006.

[3] Beumont P, Hay P, Beumont D, et al. Australian and New Zealand clinical practice guidelines for the treatment of anorexia nervosa. Aust NZJ Psychiatry 2004; 38(9): 659-70.

[4] American Academy of Pediatrics. Committee on Adolescence. Identifying and treating eating disorders. Pediatrics 2003; 111(1): 204-11.

http://dx.doi.org/10.1542/peds.111.1.204

[5] Beecham J, Chisholm D, O'Herlihy A, Astin J. Variations in the costs of child and adolescent psychiatric in-patient units. Br J Psychiatry: J Mental Sci 2003; 183: 220-5; discussion 226-7.

[6] Dominguez J, Goodman L, Sen Gupta S, et al. Treatment of anorexia nervosa is associated with increases in bone mineral density, and recovery is a biphasic process involving both nutrition and return of menses. Am J Clin Nutr 2007; 86(1): 92-99.

[7] Katzman DK, Christensen B, Young AR, Zipursky RB. Starving the brain: Structural abnormalities and cognitive impairment in adolescents with anorexia nervosa. Semin Clin Neuropsychiatry $2001 ; 6(2): 146-52$.

http://dx.doi.org/10.1053/scnp.2001.22263

[8] Berkman ND, Lohr KN, Bulik CM. Outcomes of eating disorders: A systematic review of the literature. Int $\mathrm{J}$ Eat Disord 2007; 40(4): 293-309. http://dx.doi.org/10.1002/eat.20369

[9] Golden NH, Meyer W. Nutritional rehabilitation of anorexia nervosa. goals and dangers. Int J Adolesc Med Health 2004; 16(2): 131-44.

http://dx.doi.org/10.1515/IJAMH.2004.16.2.131

[10] Birmingham CL, Su J, Hlynsky JA, Goldner EM, Gao M. The mortality rate from anorexia nervosa. Int J Eat Disord 2005; 38(2): 143-46.

http://dx.doi.org/10.1002/eat.20164

[11] Mattar L, Huas C, Duclos J, Apfel A, Godart N. Relationship between malnutrition and depression or anxiety in Anorexia nervosa: A critical review of the literature. J Affect Disord 2011; 132(3): 311-18.

http://dx.doi.org/10.1016/j.jad.2010.09.014

[12] Russell J. Management of anorexia nervosa revisited. BMJ (Clinical Research Ed.) 2004; 328(7438): 479-80.

http://dx.doi.org/10.1136/bmj.328.7438.479

[13] Fichter MM, Quadflieg N, Hedlund S. Twelve-year course and outcome predictors of anorexia nervosa. Int J Eat Disord 2006; 39(2): 87-100.

http://dx.doi.org/10.1002/eat.20215

[14] Papadopoulos FC, Ekbom A, Brandt L, Ekselius L. Excess mortality, causes of death and prognostic factors in anorexia nervosa. Br J Psychiatry 2009; 194: 10-17. http://dx.doi.org/10.1192/bip.bp.108.054742 
[15] Harbottle EJ, Birmingham CL, Sayani F. Anorexia nervosa: A survival analysis. Eat Weight Dis 2008; 13(2): e32-4.

[16] Hoek HW. Incidence, prevalence and mortality of anorexia nervosa and other eating disorders. Curr Opin Psychiatry 2006; 19(4): 389-94.

http://dx.doi.org/10.1097/01.yco.0000228759.95237.78

[17] Lindblad F, Lindberg L, Hjern A. Improved survival in adolescent patients with anorexia nervosa: A comparison of two Swedish national cohorts of female inpatients. Am J Psychiatry 2006; 163(8): 1433-35.

http://dx.doi.org/10.1176/appi.ajp.163.8.1433

[18] Steinhausen HC. The outcome of anorexia nervosa in the 20th century. Am J Psychiatry 2002; 159(8): 1284-93. http://dx.doi.org/10.1176/appi.ajp.159.8.1284

[19] Darby AM, Hay PJ, Mond JM, Quirk F. Community recognition and beliefs about anorexia nervosa and its treatment. Int J Eat Disord 2012; 45(1): 120-24. http://dx.doi.org/10.1002/eat.20886

[20] Walsh JME, Wheat ME, Freund K. Detection, Evaluation, and Treatment of Eating Disorders. The Role of the Primary Care Physician. Gen Intern Med 2000; 15(8): 577-90. http://dx.doi.org/10.1046/j.1525-1497.2000.02439.x

[21] Sim LA, McAlpine DE, Grothe KB, Himes SM, Cockerill RG, Clark MM. Identification and treatment of eating disorders in the primary care setting. Mayo Clin Proc 2010; 85(8): 746-51. http://dx.doi.org/10.4065/mcp.2010.0070

[22] Diagnostic and statistical manual of mental disorders. 4th ed. DSM-IV-TR. Washington, DC: American Psychiatric Association, 2000.

[23] Mathew A, Chiemprabha AF, Donelson S. Hyperamylasemia. (Accessed October 11, 2010 at http://www.emedicine. medscape.com/article/186389-overview).
[24] Miller KK, Grinspoon SK, Ciampa J, Hier J, Herzog D, Klibanski A. Medical findings in outpatients with anorexia nervosa. Arch Intern Med 2005; 165(5): 561-6. http://dx.doi.org/10.1001/archinte.165.5.561

[25] Katzman DK. Medical complications in adolescents with anorexia nervosa: a review of the literature. Int J Eat Disord 2005; 37: S52-S59.

http://dx.doi.org/10.1002/eat.20118

[26] Morris J, Twaddle S. Anorexia nervosa. BMJ (Clinical Research Ed.) 2007; 334(7599): 894-98. http://dx.doi.org/10.1136/bmj.39171.616840.BE

[27] Gentile MG, Pastorelli P, Ciceri R, Manna GM, Collimedaglia S. Specialized refeeding treatment for anorexia nervosa patients suffering from extreme undernutrition. Clin Nutr 2010; 29(5): 627-32. http://dx.doi.org/10.1016/j.clnu.2010.03.008

[28] Gentile MG, Manna GM, Ciceri R, Rodeschini E. Efficacy of inpatient treatment in severely malnourished anorexia nervosa patients. Eat Weight Disord 2008; 13: 191-97.

[29] Vignaud M, Constantin JM, Ruivard M, et al. Refeeding syndrome influences outcome of anorexia nervosa patients in intensive care unit: an observational study. Crit Care 2010; 14: R172. http://dx.doi.org/10.1186/cc9274

[30] Gaudiani, JL, Sabel AL, Mascolo M, Mehler PS. Severe anorexia nervosa: Outcomes from a medical stabilization unit. Int J Eat Disord 2012; 45(1): 85-92. http://dx.doi.org/10.1002/eat.20889

\section{DOI: http://dx.doi.org/10.6000/1929-5634.2012.01.01.7}

(C) 2012 Gentile et al.; Licensee Lifescience Global.

This is an open access article licensed under the terms of the Creative Commons Attribution Non-Commercial License (http://creativecommons.org/licenses/by-nc/3.0/) which permits unrestricted, non-commercial use, distribution and reproduction in any medium, provided the work is properly cited. 